\title{
An Investigation of Self-reported Health-related Productivity Loss in Office Workers and Associations With Individual and Work-related Factors Using an Employer's Perspective
}

\author{
Michelle Jessica Pereira, MPhty (Sports Physiotherapy), Venerina Johnston, PhD, Leon Melville Straker, PhD, \\ Gisela Sjøgaard, PhD, Markus Melloh, MD, PhD, Shaun Patrick O'Leary, PhD, \\ and Tracy Anne Comans, PhD
}

\begin{abstract}
Objective: Office workers have a high prevalence of musculoskeletal conditions. This can be a significant economic burden due to health-related productivity loss. Individual and work-related factors related to office worker health-related productivity were investigated. Methods: A survey including the Health and Work Performance Questionnaire, which estimated productivity loss, also recorded individual and work-related factors with potential associations with health-related productivity. Muscle function and workstation ergonomics were examined through physical assessments. Linear models investigated the relationships between these factors and health-related productivity. Results: Significant factors identified were occupational category $(0.001<P<0.050)$, job satisfaction $(P<0.001)$, psychological wellbeing $(P=0.031)$, and musculoskeletal pain $(P=0.023)$. Health-related productivity loss was greater in office workers working as managers, with lower job satisfaction and psychological wellbeing, and those with musculoskeletal pain. Conclusion: Office worker health-related productivity loss is represented by a combination of both individual and workrelated factors.
\end{abstract}

$\mathrm{H}$ ealth-related productivity loss represents a significant component of human capital expenditure for employers, ${ }^{1}$ estimated to cost around $\$ 260$ billion dollars annually in the United States. $^{2}$ Office workers may be particularly vulnerable to healthrelated productivity loss due to their high prevalence of musculoskeletal pain, up to $70 \%$ annually. ${ }^{3,4}$ Several individual and

From Health Services and Outcomes Research, National Healthcare Group Singapore (Ms Pereira), Physiotherapy, School of Health and Rehabilitation Sciences, The University of Queensland, Brisbane, Queensland, Australia (Ms Pereira, Drs Johnston, O'Leary), School of Physiotherapy and Exercise Science, Curtin University, Perth, Western Australia, Australia (Dr Straker), Department of Sport Sciences and Clinical Biomechanics, Faculty of Health Sciences, University of Southern Denmark, Odense, Denmark (Dr Sjøgaard), Centre for Medical Research, The University of Western Australia, Perth, Western Australia, Australia (Dr Melloh), Curtin Medical School, Curtin University, Perth, Western Australia, Australia (Dr Melloh), Institute of Health Sciences, Zurich University of Applied Sciences, Winterthur, Switzerland (Dr Melloh), Department of Physiotherapy, Royal Brisbane and Women's Hospital, Queensland Health, Brisbane, Queensland, Australia (Dr O'Leary), Menzies Health Institute Queensland, Griffith University, Meadowbrook, Brisbane, Queensland, Australia (Dr Comans), and Metro North Hospital and Health Service, Herston, Brisbane, Queensland, Australia (Dr Comans).

The National Health and Medical Research Council (NHMRC) of Australia under Grant \#12609000051246 supported this work. Ms Pereira is supported by an Australian Postgraduate Award and Professor Straker is supported by a NHMRC senior research fellowship (\#1019980).

MJP, VJ, TAC formulated the research question and outlined the research design. MJP analyzed the data, reviewed the existing literature, and drafted the manuscript. VJ, LMS, GS, MM, SPO, and TAC critically reviewed and revised the manuscript. All authors read and approved the final manuscript. The authors declare that they have no competing interests.

Address correspondence to: Michelle Jessica Pereira, MPhty (Sports Physiotherapy), Health Services and Outcomes Research, National Healthcare Group, Singapore 138543, Singapore (michelle jessica_pereira@nhg.com.sg).

Copyright (C) 2017 American College of Occupational and Environmental Medicine

DOI: 10.1097/JOM.0000000000001043 work-related factors have been linked with musculoskeletal symptoms in office workers. Factors such as increased psychological stress, reduced neck movement, altered muscle activity, reduced physical activity levels, suboptimal work ergonomics, and longer computer work hours have been associated with an increased risk of musculoskeletal symptoms in office workers. ${ }^{3,5-9}$ The ubiquity of computers in the workplace increases the exposure of office workers to postural strain and risk of musculoskeletal symptoms. ${ }^{10}$ Musculoskeletal symptoms are associated with diminishing health-related productivity. ${ }^{11,12}$ Thus, it is plausible that individual and workrelated factors may also impact on health-related productivity levels in office workers with musculoskeletal symptoms.

Significant relationships between worker productivity and various health conditions have been documented, including stress and depression, spinal pain, allergies, obesity, and diabetes. ${ }^{13-17}$ The impact of health conditions on productivity appears to be cumulative in nature, with different conditions associated with varying levels of productivity loss. ${ }^{18}$ Health-related productivity can also be influenced by individual factors. Lower physical activity levels and unfavorable work-related health beliefs have also been linked with lower health-related productivity levels. ${ }^{19-22}$ Unfortunately, a holistic understanding of individual and work-related factors influencing health-related productivity is lacking, especially in specific occupational groups. Such knowledge would be informative to industry and research settings aiming to lessen the financial impact of worker health-related productivity loss.

Measurement of worker health-related productivity is challenging despite the known association between poor health and reduced worker productivity. Ill health can reduce productivity through two distinct forms, namely, "sickness absenteeism" from work due to sick leave, and impaired at-work performance termed "sickness presenteeism," ${ }^{23}$ hereafter these terms will be used without "sickness" being specified. From an employer's perspective, both absenteeism and presenteeism effects are relevant to healthrelated productivity. ${ }^{24}$ Many industries do not have objective measures of productivity ${ }^{25}$ and a comprehensive review of 21 health-related productivity measures did not identify any clear gold standard. ${ }^{26}$ Quantifying productivity loss in monetary terms due to various worker health states is complicated by different job positions and associated incomes, with no standardized measure of output across industries. This difficulty is augmented in office workers who include a heterogeneous mix of occupations working in an office environment using computer equipment for diverse work tasks ${ }^{27}$ with no standardized measure of job output. However, it is in the economic interest of the employers of office workers to maximize the health of their workforce to prevent potential healthrelated productivity loss and negative financial outcomes. ${ }^{13}$

The aim of this study was to identify individual and workrelated factors associated with health-related productivity levels in office workers from an employer's perspective, with a focus on musculoskeletal health. We hypothesized that both individual and work-related factors would be associated with health-related 
productivity. These relationships have not been previously adequately studied. Therefore, we anticipate that the findings of the study will be potentially informative to employers of office workers seeking to minimize health-related productivity loss.

\section{METHODS}

\section{Design}

A cross-sectional study using a self-report online survey and individual physical assessments was performed. The data were sourced from the baseline observations from a prospective 1-year longitudinal, parallel cluster, randomized controlled trial (RCT) conducted from June 2013 to July 2016. This trial compared two types of combined workplace programs for office workers (ACTRN12612001154897), comprising of an ergonomics intervention along with specific neck exercise and an ergonomics intervention and health education programs. The details of the trial protocol have been published. ${ }^{28}$ Ethical approval from the Human Ethics Unit of the University of Queensland was obtained before commencement.

\section{Participants}

Eligible participants were office workers older than 18 years, working more than 30 hours weekly, without medical conditions that fell under the exclusion criteria of the RCT. Participants were excluded if they were pregnant, or had health conditions such as previous trauma or injuries to the neck, specific cervical pathologies, inflammatory conditions, or any history of cervical spine surgery. Participants were also excluded if exercise was contraindicated by their medical provider, or if they would be absent from their usual workplace for more than 2 weeks during the 12 -week activity period of the RCT.

\section{Recruitment}

Participants were recruited from both public and private sectors, specifically organizations employing large numbers of office workers in an Australian metropolitan city and its surrounds (Brisbane, Queensland). Organizations were recruited through established professional networks of the lead investigator (VJ) and promotion of the trial through scientific and industry conferences. To minimize participant response bias and maximize generalizability of results, the trial was presented as a primary prevention program for health enhancement. Within each organization, participants were recruited through internal email communication sent from each site-based designated liaison, or scheduled information sessions ran by research team members located in Brisbane.

\section{Procedure}

Once eligibility for the trial was established, an online survey was administered to participants. Participants then undertook two types of physical assessments performed by trained physiotherapists or occupational therapists. Informed consent was obtained before commencement of these physical assessments.

\section{Measures}

\section{Health-related Productivity Loss}

The primary outcome measure of health-related productivity loss was obtained using the World Health Organization's Health and Work Performance Questionnaire (HPQ). This questionnaire formulates the monetary impact of self-reported health-related productivity loss from both sickness absences and impaired performance at work or presenteeism. This questionnaire has a good agreement with measures of work performance from an employer's perspective. ${ }^{29,30}$ The number of days missed from work in the last 28 days, self-rated usual job performance without reference to peers, or absolute presenteeism in the last 28 days, and income information obtained from participants were used to monetize total self-reported health-related productivity loss, from both absenteeism and presenteeism, for each participant. The approach selected utilized an employer's perspective. ${ }^{31}$ The HPQ provides several ways of calculating presenteeism. The absolute form of presenteeism was selected, as it has the highest levels of correlations to health markers compared with other forms. ${ }^{32}$ Healthrelated productivity loss was calculated in both the original units of measurement of the HPQ in terms of work days missed and monetized values. Information in terms of work days missed allows easy comparisons with other settings, for example, varying geographical locations utilizing different currencies. In addition, specific contributions from both absenteeism and presenteeism were also tabulated.

\section{Individual Factors - Collected Through Online Survey}

A body diagram was used to demarcate anatomical areas of the neck, right and left shoulder, upper back, elbows, wrist and hands, low back, hips or thighs, knees, and ankles or feet. The severity of musculoskeletal symptoms in the preceding week was measured with a validated and reliable 10-point scale ranging from 0 (No symptoms) to 9 (worst imaginable symptoms). ${ }^{33}$ Participants who reported a score equal or more than 3 in a particular region were classified as symptomatic cases of that region and those who scored less (0 to 2), as asymptomatic individuals. ${ }^{34,35}$ The total number of symptomatic musculoskeletal regions was summed for each participant. Those who reported one or more symptomatic musculoskeletal area were defined as "cases" and those who did not report any site of musculoskeletal symptoms were defined as "non-cases."

The Neck Disability Index (NDI) is a valid and reliable instrument to quantify an individual's level of neck-related disability. ${ }^{36}$ This measure was included due to specific interest regarding the impact of neck symptoms on daily function and potential consequence on health-related productivity due to the high prevalence of neck pain in office workers.

Demographic information such as age, gender, body mass index, annual income, and occupational categories appropriate for office workers ${ }^{4}$ were collected. Personal factors hypothesized to have an impact on health-related productivity levels in office workers were also collected. These included medication use for neck pain, presence of other health conditions, personal health beliefs regarding work-related activity using a single item from the Fear-Avoidance Beliefs Questionnaire (FABQ), ${ }^{37}$ level of psychological wellbeing using the valid and reliable Kessler 6 scale (K6), ${ }^{38}$ and physical activity levels with the valid and reliable short form of International Physical Activity Questionnaire (IPAQ) ${ }^{39}$ whereby participants were categorized as being "inactive," "meeting activity guidelines," or "exceeding activity guidelines."

\section{Individual Factors-Collected Through Physical Assessments}

The neck and shoulder muscle function of participants was assessed using previously described methods. ${ }^{28}$ Specifically, maximum endurance strength of the neck flexors, neck extensors, and shoulder abductors was recorded. These measurement techniques performed in this study had been shown by Chen X, O'leary S and Johnston $\mathrm{V}$ to have excellent test-retest reliability (intra-class correlation coefficients 0.80 to 0.96 ) (Unpublished data, 2017).

\section{Work-related Factors-Collected Through Online Survey}

Indicators of work-related stressors that could potentially affect self-reported health-related productivity included selfreported duration of daily computer work and overall job 
satisfaction, evaluated with a single pictorial item. ${ }^{40}$ Workplace psychosocial risks were assessed using a modified 18-item version of the Job Content Questionnaire (JCQ). Participants were grouped into different job strain categories (low strain, active, passive, or high strain jobs) using the scoring recommended by Ostry. ${ }^{41}$

\section{Work-related Factors-Collected Through Physical Assessments}

Participants also underwent an ergonomics evaluation of their workstation. ${ }^{42,43}$ This assessment was performed using a comprehensive observational checklist consistent with local legislative requirements that possessed moderate to good inter-rater reliability. ${ }^{44}$ The total score (range 0 to 38 ) was used as an indication of the overall suitability of a participant's workstation for their individual needs and job demands.

\section{Statistical Analysis}

All statistical analyses were conducted with Stata version 14 (Stata Corporation, College Station, TX). Generalized linear models (GLMs), using a gamma distribution and an identity link, were used to account for the non-normal distribution of economic valuation data and preserve coefficients in an interpretable dollar value form. Univariate analyses were first conducted to examine the associations of monetized health-related productivity loss with individual and work-related factors. Factors with associations that approached significance $(P<0.2)$ in univariate analyses were then examined for multicollinearity using the variance inflation factor (VIF) set at 2 VIF or less. All factors with significant univariate associations with monetized levels of productivity loss, and potential confounders, and of those without multicollinearity issues, were then entered into a final stepwise backwards GLM (gamma distribution, identity link) with a significance level set at 0.1 to identify factors that were significantly $(P<0.05)$ related to monetized health-related productivity loss in a multivariate GLM.

\section{RESULTS}

\section{Participant Cohort and Characteristics}

Of the 14 participating organizations, 763 volunteer office workers who met the eligibility criteria were randomly allocated to an intervention and provided data. Analyses for this study were performed on complete data from 695 participants. Sixty-eight participants were not included in the final analysis for the following reasons: additional information provided through the online survey or during physical assessments leading to ineligibility $(n=6)$; withdrawal from the RCT $(n=3)$; discontinued participation in the RCT before completion of survey or physical assessments, with resulting lack of data, due a change of employer $(n=4)$, excessive work demands $(n=2)$, unrelated illness or injury $(n=2)$, or no reason provided $(n=5)$. Information regarding other types of missing data points required for final analysis is outlined in Appendix 1.

Table 1 summarizes all demographic and information of both individual and work-related factors collected from participants through the online survey. The average gross individual income in Australian dollars was $\$ 86,700(\mathrm{SD}=\$ 38,000)$, substantially higher than the Australian average yearly earnings of $\$ 53,045 .{ }^{45}$ There was also a significant correlation between occupational category and annual income found (Spearman rho 0.580, $P<0.001$ ). Mean participant K6 score was 3.72 . Only $1.73 \%$ of participants were classified as experiencing high psychological stress, represented by K6 scores of 13 or greater. The results from the individual physical assessments undertaken by participants are listed in Table 2.
TABLE 1. Characteristics of the Study Population Collected From Online Survey $(N=695)$

\begin{tabular}{|c|c|}
\hline Characteristic & $\begin{array}{l}\text { Mean (SD), Unles } \\
\text { Otherwise Stated }\end{array}$ \\
\hline \multicolumn{2}{|l|}{ Individual factors } \\
\hline Sex (female count, percent) & $433(62.3 \%)$ \\
\hline Age in years & $42.5(10.7)$ \\
\hline $\begin{array}{l}\text { Body mass index-from self-reported } \\
\text { height and weight })(n=694)\end{array}$ & $27.0(5.79)$ \\
\hline $\begin{array}{l}\text { Gross annual individual income } \\
\text { (\$AUD) }\end{array}$ & $\$ 86,700(\$ 38,000)$ \\
\hline \multicolumn{2}{|l|}{ Industry category (count, percentage) } \\
\hline Private sector & $202(26.5 \%)$ \\
\hline Nonprivate sector & $561(73.5 \%)$ \\
\hline \multicolumn{2}{|l|}{ Occupation category (count, percentage) } \\
\hline Manager/Senior official & $127(18.3 \%)$ \\
\hline Professional & $212(30.5 \%)$ \\
\hline $\begin{array}{l}\text { Associate professional/Technical } \\
\text { occupation }\end{array}$ & $75(10.7 \%)$ \\
\hline Administrative/Secretarial occupation & $222(32.0 \%)$ \\
\hline Personal service/Others & $60(8.63 \%)$ \\
\hline $\begin{array}{l}\text { Number of participants who reported } \\
\text { use of medication for neck pain } \\
\text { (count, percent) }\end{array}$ & $121(17.4 \%)$ \\
\hline $\begin{array}{l}\text { Number of medical conditions } \\
\text { reported (median, IRQ) }\end{array}$ & $0(0,1)$ \\
\hline $\begin{array}{l}\text { Participants who held belief of work } \\
\text { is cause of pain (FABQ work- } \\
\text { related activity item score }=6 \text { ) } \\
\text { (count, percent) }\end{array}$ & $77(10.4 \%)$ \\
\hline $\begin{array}{l}\text { Levels of psychological wellbeing- } \\
\text { K6 scores }{ }^{\dagger}\end{array}$ & $3.72(3.28)$ \\
\hline $\begin{array}{l}\text { Number of participants reporting } \\
\text { "high levels of psychological } \\
\text { stress"** }\end{array}$ & $12(1.73 \%)$ \\
\hline \multicolumn{2}{|c|}{ Levels of physical activity_short form of IPAQ categories (count, percentage) } \\
\hline "Inactive" & $241(34.7 \%)$ \\
\hline "Meeting guidelines" & $380(54.7 \%)$ \\
\hline "Exceeding guidelines" & $74(10.7 \%)$ \\
\hline $\begin{array}{l}\text { Number of participants who reported } \\
\text { at least one musculoskeletal pain } \\
\text { site/"cases" of musculoskeletal } \\
\text { pain (count, percentage) }\end{array}$ & $491(70.7 \%)$ \\
\hline $\begin{array}{l}\text { Number of symptomatic } \\
\text { musculoskeletal regions reported by } \\
\text { cohort }\end{array}$ & $2.01(2.08)$ \\
\hline $\begin{array}{l}\text { Number of symptomatic } \\
\text { musculoskeletal regions reported by } \\
491 \text { who reported experiencing at } \\
\text { least } 1 \text { area of musculoskeletal pain } \\
\text { or "cases" }\end{array}$ & $2.85(1.94)$ \\
\hline $\begin{array}{l}\text { Levels of neck disability—NDI } \\
\text { scores }^{\ddagger}\end{array}$ & $9.63(8.41)$ \\
\hline \multicolumn{2}{|c|}{ Work-related factors } \\
\hline \multicolumn{2}{|c|}{ Time using computer at work (count, percentage) } \\
\hline 4 to $<6$ hours/day & $118(17.0 \%)$ \\
\hline 6 to $<8$ hours/day & $490(70.5 \%)$ \\
\hline$\geq 8$ hours/day & $87(12.5 \%)$ \\
\hline Levels of overall job satisfaction ${ }^{\S}$ & $4.94(1.13)$ \\
\hline \multicolumn{2}{|c|}{ Workplace psychosocial risks_JCQ categories (count, percentage) } \\
\hline "Low strain" jobs & $134(19.3 \%)$ \\
\hline "Active" jobs & $240(34.5 \%)$ \\
\hline "Passive" jobs & $130(18.7 \%)$ \\
\hline "High strain" jobs & $191(27.5 \%)$ \\
\hline
\end{tabular}

FABQ, Fear-Avoidance Beliefs Questionnaire; IRQ, interquartile range; K6, Kessler 6 scale; SD, standard deviation.

*Defined by $\geq 12$ on Kessler 6 scale; IPAQ: International Physical Activity Questionnaire; NDI: Neck Disability Index; JCQ: Job Content Questionnaire.

${ }^{\dagger}$ Higher scores represent higher levels of psychological stress.

${ }^{\ddagger}$ Higher percentage scores represent higher levels of neck disability.

${ }^{\S}$ Higher scores represent higher levels of overall job satisfaction. 
TABLE 2. Results of Individual Physical Assessments Undertaken by Participants

\begin{tabular}{|c|c|c|c|}
\hline Type of Physical Assessment & Measurement Unit & Number of Participants & Mean (SD) \\
\hline Maximum endurance of neck flexors & Time in seconds holding $50 \% \mathrm{MVC}$ & 692 & $41.4(20.3)$ \\
\hline Maximum endurance of neck extensors & Time in seconds holding $50 \%$ MVC & 694 & $88.8(62.9)$ \\
\hline Ergonomics evaluation & Overall checklist score out of maximum of $38^{*}$ & 667 & $31.7(3.00)$ \\
\hline
\end{tabular}

MVC, maximum voluntary contraction; SD, standard deviation.

${ }^{*}$ Higher scores represent higher fulfillment of workstation equipment to ergonomic assessment used.

\section{Self-reported Health-related Productivity Loss}

Table 3 illustrates self-reported health-related productivity loss from participants. The monetary burden of overall health-related productivity loss is primarily driven by the costs of presenteeism, with presenteeism costing approximately 5.95 times more than absenteeism. Participants had on average less than 1 day missed from work in the previous 28-day period due to absenteeism, and the equivalent number of work days missed due to presenteeism was approximately 5.36 times than that of absenteeism.

\section{GLMs for Monetized Health-related Productivity Loss}

Univariate GLMs identified several individual factors as having significant associations with monetized health-related productivity loss $(P<0.05)$ and none with associations that approached significance $(0.05<P<0.2)$. The remaining had nonsignificant associations $(P>0.2)$. Significant factors identified were gender, the presence of musculoskeletal pain, NDI scores, K6 scores and shoulder abductor muscle endurance. Significant work-related factors were levels of job satisfaction and occupational category. All these factors when examined did not present issues with multicollinearity. The results of the final model are summarized in Table 4. In order of magnitude of coefficients obtained in the final multivariate GLM, health-related productivity loss was significantly associated with occupational category to $(-567$ to -174$)$, levels of job satisfaction (-137), levels of psychological stress (20.9), and experiencing at least one area of musculoskeletal pain in the preceding week (117). On the basis of these coefficients obtained, the potential financial burden of musculoskeletal pain is estimated to be costing employers on average $\$ 1520$ annually per office worker experiencing musculoskeletal pain.

\section{DISCUSSION}

This study identified individual and work-related factors associated with health-related productivity levels in office workers. Specifically, health-related productivity loss was greater in those who worked as managers or senior officials, reported lower job satisfaction, higher levels of psychological stress, and experienced at least one area of musculoskeletal pain in the last 7 days. As most of these factors are potentially modifiable, the findings may have direct application for employers designing workplace health initiatives to improve health-related productivity in office workers. For example, addressing individual factors has previously been advocated as a key strategy in improving worker productivity. ${ }^{46}$

A key finding of this study is that the impact of presenteeism is nearly six times greater than that of absenteeism in office workers in both monetized terms and in equivalent work days missed. This finding echoes previous research. ${ }^{1}$ It should be acknowledged that the concept of presenteeism is still evolving in the scientific literature. This is especially the case for office workers who perform heterogeneous work, partly due to differing job roles or seniority, and the corresponding varied work demands. This is despite the physiological and physical demands of office work generally being considered to be low and unvaried. However, the burden of employee health-related productivity on overall organization performance would be underestimated if employers only considered absenteeism as a measure of worker health-related productivity. Therefore, it is essential for employers of office workers to consider presenteeism costs in order to comprehensively maximize worker health-related productivity, which is an integral aspect of an organization's capacity to optimize organizational performance. ${ }^{47-49}$

The variance in health-related productivity loss in office workers in this study was partially explained by a combination of work-related (occupation, job satisfaction) and individual (presence of musculoskeletal pain, psychological stress) factors. The finding that managers or senior officials are more likely to report higher levels of health-related productivity loss has been reported previously and possibly reflects the more complex job demands and responsibilities associated with these positions, leading to a larger scope for poorer performance in these more senior positions with potentially larger productivity decrements. ${ }^{32}$ This finding could also be explained by the significant (albeit moderate) correlation between occupational category and income, which would also be expected to influence the productivity outcomes found in this study. The burden of health-related productivity loss arising from absenteeism and presenteeism in equivalent work days missed was also similar in magnitudes, without the influence of income, supporting

TABLE 3. Results of Health-related Productivity Loss for the Past 4 Weeks $(N=695)$

\begin{tabular}{|c|c|c|c|}
\hline Component of Health-Related Productivity Losses & Mean (SD) & Median & Maximum \\
\hline Total monetary value (AUD) & $\$ 1,420(\$ 972)$ & $\$ 1,220$ & $\$ 6,330$ \\
\hline Monetary value due to absenteeism (AUD) & $\$ 205(\$ 393)$ & 0 & $\$ 5,460$ \\
\hline Monetary value due to presenteeism (AUD) & $\$ 1,220(\$ 902)$ & $\$ 1,060$ & $\$ 5,880$ \\
\hline Total work days missed & $4.21(2.40)$ & 3.90 & 20 \\
\hline Work days missed due to absenteeism & $0.662(1.29)$ & 0 & 20 \\
\hline Equivalent work days missed due to presenteeism & $3.55(2.08)$ & 3.60 & 14.4 \\
\hline
\end{tabular}

Tabulated with World Health Organization Health and Work Performance Questionnaire and income information provided by participants. 
TABLE 4. Results of Generalized Linear Multivariate Model for Monetized Health-related Productivity Loss ( $N=695)$

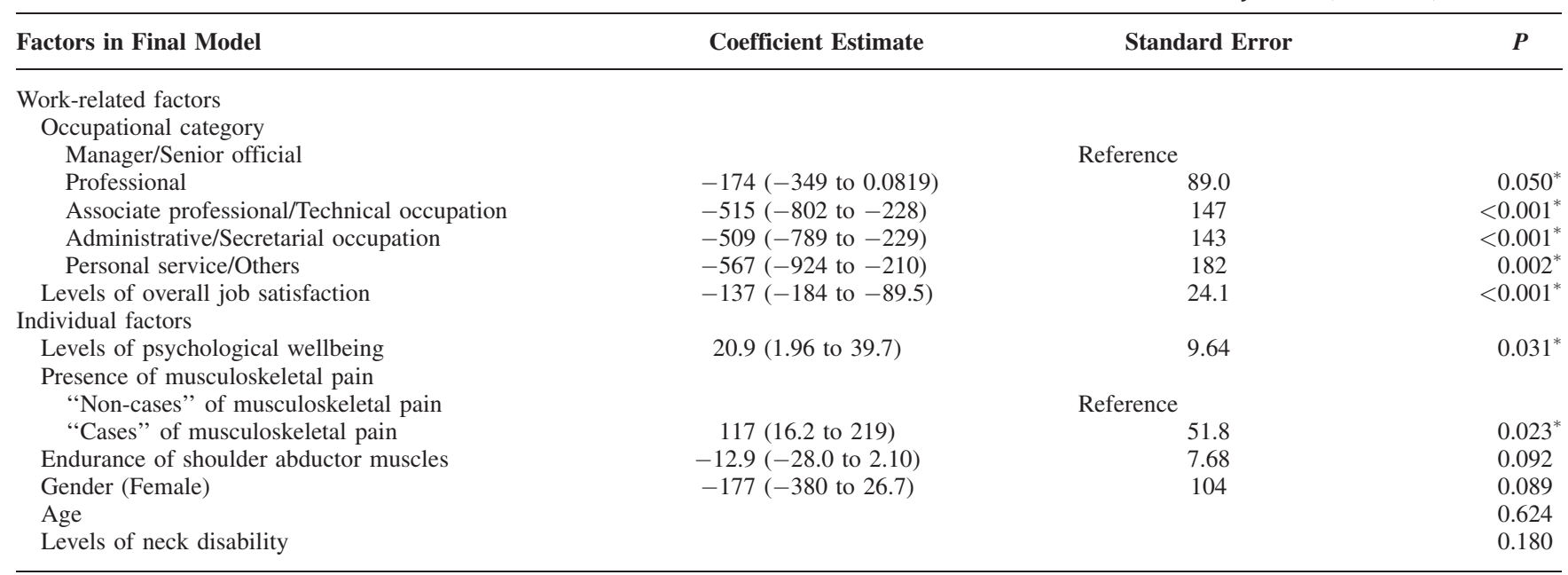

Modeling was performed using gamma distribution and identity link (Robust standard error adjusted for 14 clusters in organization).

${ }^{*}$ Factors identified to be significantly associated with monetized health-related productivity loss $(P<0.05)$. Factors with significant associations with monetized health-related productivity loss have been listed in order of coefficients magnitude.

that an individual's income would not significantly change the main results of the study. Physical factors may also play a role in the relationship between occupational category and health-related productivity loss. Matching an individual's physical abilities to the physical demands of their occupation has been proposed for better occupational health intervention outcomes. ${ }^{50}$ Future studies will need to investigate the causal relationship between the physical demands imposed by occupational category, physical capacity of the worker, and health-related productivity loss.

In agreement with previous studies, lower job satisfaction was shown to be associated with greater health-related productivity loss. ${ }^{51,52}$ Workplace health interventions can improve job satisfaction, ${ }^{53}$ though the mechanism for this is likely through supporting an individual's psychological wellbeing. ${ }^{54}$ A recent Australian study found that health-related productivity loss was significantly greater when psychological stress was concomitant with other health conditions across several occupational groups. ${ }^{55}$ Workplace mental health programs are not commonplace, ${ }^{56}$ probably due to a lack of perceived need for such programs by organization leaders. ${ }^{57}$ This is despite studies showing the treatment of psychological stress can restore health-related productivity levels to near normal. ${ }^{58}$ Although only a small proportion of participants were classified as experiencing high psychological stress, the associated negative financial impact of impaired psychological health is significant enough to warrant employers to provide workplace interventions targeting psychological health to improve employee health-related productivity. $23,59,60$

The estimated negative financial impact of musculoskeletal pain calculated in this study cannot be ignored by employers of office workers. Compounded by a high prevalence of musculoskeletal pain found in this cohort of office workers at $70.7 \%$ of participants reporting at least one site of musculoskeletal pain in the preceding week, this poses a significant financial issue for employers. The magnitude of this issue is evident given that at least $10 \%$ of the Australian metropolitan fulltime workforce is regarded as "office workers." This figure is also likely to be an underestimation of the actual number of workers using computer technology on a regular basis. ${ }^{6}$ The combination of the estimated value of health-related productivity loss from musculoskeletal pain, potential future loss from diminished long-term working ability, ${ }^{61}$ together with the sheer numbers of office workers in various industries, makes musculoskeletal pain in office workers a significant global economic burden warranting attention from employers and researchers alike.

\section{Strengths and Limitations}

A key strength of this study was that the primary outcome of health-related productivity loss was estimated with the HPQ that has been used in investigations of several other working populations. ${ }^{59,62,63}$ This was in addition to the comprehensive inclusion of individual and work-related assessments using self-report and physical assessment methods.

The findings from this study may be significantly influenced by the sample recruited and the study design. First, the mean income of this study sample was skewed toward a higher-than-average income than that of the general Australian population. Thus, the health-related productivity cost findings obtained are likely to be above mean values that would be obtained from a random sample of the general population. Second, the presenteeism measure used for this study is not specific to health and encompasses a global overview of reduced at-work performance, warranting a conservative interpretation of the results, as actual sickness presenteeism may be lower. ${ }^{64}$ Lastly, the adoption of an employer's perspective could have biased estimations to higher levels when calculating the financial costs of health-related productivity loss, as the approach taken does not account for participants making up for missed work days with overtime on other days. However, the size of coefficient estimates obtained in this study appears reasonable and does not look to be overly inflated.

\section{CONCLUSION}

Both individual and work-related factors were shown to be associated with health-related productivity levels in office workers. In order of magnitude of health-related productivity loss estimates, factors with significant associations were being a senior manager or official, lower job satisfaction, poorer psychological wellbeing, and the presence of musculoskeletal pain. The monetary burden of presenteeism in this sample of office workers was approximately six times more than absenteeism. These findings suggest that financial gains may be achieved through workplace health interventions that target these potentially modifiable individual and work-related factors in office workers. 


\section{ACKNOWLEDGMENT}

The authors thank the participating organizations for their support of this research study, Ms Alyssa Welch (Project Manager), Ms Xiaoqi Chen (PhD candidate), and Ms Jessica Larkin (Physiotherapist) for their contributions to data collection and management.

\section{REFERENCES}

1. Collins JJ, Baase CM, Sharda CE, et al. The assessment of chronic health conditions on work performance, absence, and total economic impact for employers. J Occup Environ Med. 2005;47:547-557.

2. Davis K, Collins SR, Doty MM, Ho A, Holmgren AL. Health and Productivity Among U.S. Workers. Issue brief (Commonw Fund). 2005;856:1-12.

3. Johnston V, Souvlis T, Jimmieson NL, Jull G. Associations between individual and workplace risk factors for self-reported neck pain and disability among female office workers. Appl Ergon. 2008;39:171-182.

4. Griffiths KL, Mackey MG, Adamson BJ. Behavioral and psychophysiological responses to job demands and association with musculoskeletal symptoms in computer work. J Occup Rehabil. 2011;21:482-492.

5. Cagnie B, Danneels L, Van Tiggelen D, De Loose V, Cambier D. Individual and work related risk factors for neck pain among office workers: a cross sectional study. Eur Spine J. 2007;16:679-686.

6. Hush JM, Michaleff Z, Maher CG, Refshauge K. Individual, physical and psychological risk factors for neck pain in Australian office workers: a 1-year longitudinal study. Eur Spine J. 2009;18:1532-1540.

7. Kiss P, De Meester M, Kruse A, Chavee B, Braeckman L. Neck and shoulder complaints in computer workers and associated easy to assess occupational factors: a large-scale cross-sectional multivariate study. Int Arch Occup Environ Health. 2012;85:197-206.

8. Tornqvist EW, Hagberg M, Hagman M, Risberg EH, Toomingas A. The influence of working conditions and individual factors on the incidence of neck and upper limb symptoms among professional computer users. Int Arch Occup Environ Health. 2009;82:689-702.

9. Johnston V, Jull G, Souvlis T, Jimmieson NL. Neck movement and muscle activity characteristics in female office workers with neck pain. Spine (Philadelphia Pa 1976). 2008;33:555-563.

10. Robertson MM, O’Neill MJ. Reducing musculoskeletal discomfort: effects of an office ergonomics workplace and training intervention. Int J Occup Saf Ergon. 2003;9:491-502.

11. van den Heuvel SG, Ijmker S, Blatter BM, de Korte EM. Loss of productivity due to neck/shoulder symptoms and hand/arm symptoms: results from the PROMO-study. J Occup Rehabil. 2007;17:370-382.

12. Hagberg M, Vilhemsson R, Tornqvist EW, Toomingas A. Incidence of self-reported reduced productivity owing to musculoskeletal symptoms: association with workplace and individual factors among computer users. Ergonomics. 2007;50:1820-1834.

13. Boles M, Pelletier B, Lynch W. The relationship between health risks and work productivity. J Occup Environ Med. 2004;46:737-745.

14. Burton WN, Pransky G, Conti DJ, Chen C-Y, Edington DW. The association of medical conditions and presenteeism. J Occup Environ Med. 2004;46(Supplement):S38-S45.

15. Burton WN, Conti DJ, Chen C-Y, Schultz AB, Edington DW. The impact of allergies and allergy treatment on worker productivity. J Occup Environ Med. 2001;43:64-71

16. Gates DM, Succop P, Brehm BJ, Gillespie GL, Sommers BD. Obesity and presenteeism: the impact of body mass index on workplace productivity. J Occup Environ Med. 2008;50:39-45.

17. Goetzel RZ, Gibson TB, Short ME, et al. A multi-worksite analysis of the relationships among body mass index, medical utilization, and worker productivity. J Occup Environ Med. 2010;52(Suppl 1):S52-S58.

18. Burton WN, Conti DJ, Chen CY, Schultz AB, Edington DW. The role of health risk factors and disease on worker productivity. J Occup Environ Med. 1999;41:863-877.

19. van den Heuvel SG, Geuskens GA, Hooftman WE, Koppes LLJ, van den Bossche SNJ. Productivity loss at work; health-related and work-related factors. J Occup Rehab. 2010;20:331-339.

20. Proper KI, van den Heuvel SG, De Vroome EM, Hildebrandt VH, Van der Beek AJ. Dose-response relation between physical activity and sick leave. Brit J Sports Med. 2006;40:173-178.

21. van den Heuvel SG, Boshuizen HC, Hildebrandt VH, et al. Effect of sporting activity on absenteeism in a working population. Brit J Sports Med. 2005;39:e15.
22. de Vries HJ, Reneman MF, Groothoff JW, Geertzen JH, Brouwer S. Workers who stay at work despite chronic nonspecific musculoskeletal pain: do they differ from workers with sick leave? J Occup Rehabil. 2012;22: 489-502.

23. Holden L, Scuffham PA, Hilton MF, et al. Which health conditions impact on productivity in working Australians? J Occup Environ Med. 2011;53: $253-257$.

24. Pereira MJ, Coombes BK, Comans TA, Johnston V. The impact of onsite workplace health-enhancing physical activity interventions on worker productivity: a systematic review. Occup Environ Med. 2015;72:401-412.

25. Mattke S, Balakrishnan A, Bergamo G, Newberry SJ. A review of methods to measure health-related productivity loss. Am J Manag Care. 2007;13: 211-217.

26. Beaton D, Bombardier C, Escorpizo R, et al. Measuring worker productivity: frameworks and measures. J Rheumatol. 2009;36:2100-2109.

27. Ciccarelli M, Straker L, Mathiassen SE, Pollock C. Diversity of tasks and information technologies used by office workers at and away from work. Ergonomics. 2011;54:1017-1028.

28. Johnston V, O'Leary S, Comans T, et al. A workplace exercise versus health promotion intervention to prevent and reduce the economic and personal burden of non-specific neck pain in office personnel: protocol of a clusterrandomised controlled trial. J Physiother. 2014;60:233.

29. Kessler RC, Barber C, Beck A, et al. The World Health Organization Health and Work Performance Questionnaire (HPQ). J Occup Environ Med. 2003;45:156-174.

30. Kessler RC, Ames M, Hymel PA, et al. Using the World Health Organization Health and Work Performance Questionnaire (HPQ) to evaluate the indirect workplace costs of illness. J Occup Environ Med. 2004;46(Supplement): S23-S37.

31. Loeppke R, Taitel M, Haufle V, et al. Health and productivity as a business strategy: a multiemployer study. J Occup Environ Med. 2009;51:411-428.

32. Scuffham PA, Vecchio N, Whiteford HA. Exploring the validity of HPQbased presenteeism measures to estimate productivity losses in the health and education sectors. Med Decis Making. 2014;34:127-137.

33. Kaergaard A, Andersen JH, Rasmussen K, Mikkelsen S. Identication of neckshoulder disorders in a 1 year follow-up study. Validation of a questionnairebased method. Pain. 2000;86:305-310.

34. Blangsted AK, Sogaard K, Hansen EA, Hannerz H, Sjogaard G. One-year randomized controlled trial with different physical-activity programs to reduce musculoskeletal symptoms in the neck and shoulders among office workers. Scand J Work Environ Health. 2008;34:55-65.

35. Zebis MK, Andersen LL, Pedersen MT, et al. Implementation of neck/ shoulder exercises for pain relief among industrial workers: a randomized controlled trial. BMC Musculoskelet Disord. 2011;12:205.

36. Vernon H, Mior S. The Neck Disability Index: a study of reliability and validity. J Manipulative Physiol Ther. 1991;14:409-415.

37. Hoe VCW, Kelsall HL, Urquhart DM, Sim MR. Risk factors for musculoskeletal symptoms of the neck or shoulder alone or neck and shoulder among hospital nurses. Occup Environ Med. 2012;69:198-204.

38. Kessler RC, Andrews G, Colpe LJ, et al. Short screening scales to monitor population prevalences and trends in non-specific psychological distress. Psychol Med. 2002;32:959-976.

39. Craig CL, Marshall AL, Sjostrom M, et al. International physical activity questionnaire: 12-country reliability and validity. Med Sci Sports Exerc. 2003;35:1381-1395.

40. Wanous JP, Reichers AE, Hudy MJ. Overall job satisfaction: how good are single-item measures? J Appl Psychol. 1997;82:247-252.

41. Ostry AS, Radi S, Louie AM, LaMontagne AD. Psychosocial and other working conditions in relation to body mass index in a representative sample of Australian workers. BMC Public Health. 2006;6:53.

42. Martimo K-P, Shiri R, Miranda H, et al. Effectiveness of an ergonomic intervention on the productivity of workers with upper-extremity disorders: a randomized controlled trial. Scand J Work Environ Health. 2010;36:25-33.

43. Laestadius JG, Ye J, Cai X, et al. The proactive approach: is it worthwhile? A prospective controlled ergonomic intervention study in office workers. J Occup Environ Med. 2009;51:1116-1124.

44. Pereira MJ, Straker LM, Comans TA, Johnston V. Inter-rater reliability of an observation-based ergonomics assessment checklist for office workers. Ergonomics. 2016;59:1606-1612.

45. Pink B. Household income and income distribution 2011-2012. Canberra: Australian Bureau of Statistics; 2013.

46. Goetzel ZR, Shechter JD, Ozminkowski FR, et al. Promising practices in employer health and productivity management efforts: findings from a benchmarking study. J Occup Environ Med. 2007;49:111-130. 
47. Foulke J, Sherman B. Comprehensive workforce health management-not a cost, but a strategic advantage. Employ Relat Today. 2005;32:17-29.

48. Riedel J, Lynch W, Baase C, Hymel P, Peterson K. The effect of disease prevention and health promotion on workplace productivity: a literature review. Am J Health Promot. 2001;15:167-191.

49. Harte K, Mahieu K, Mallett D, Norville J, Vanderwerf S. Improving workplace productivity: it isn't just about reducing absence. Benefits $Q .2011 ; 27$ : $13-26$.

50. Holtermann A, Jørgensen MB, Gram B, et al. Worksite interventions for preventing physical deterioration among employees in job-groups with high physical work demands: background, design and conceptual model of FINALE. BMC Public Health. 2010;10:120.

51. Shah A. Internal marketing's effects on employee satisfaction, productivity, product quality, consumer satisfaction and firm performance. Am J Manag. 2014; 14:33-39.

52. Böckerman P, Ilmakunnas P. The Job Satisfaction-Productivity Nexus: a study using matched survey and register data. 2012;65:244-262.

53. Conn VS, Hafdahl AR, Cooper PS, Brown LM, Lusk SL. Meta-analysis of workplace physical activity interventions. Am J Prev Med. 2009;37:330-339.

54. Faragher EB, Cass M, Cooper CL. The relationship between job satisfaction and health: a meta-analysis. Occup Environ Med. 2005;62:105-112.

55. Holden L, Scuffham PA, Hilton MF, et al. Health-related productivity losses increase when the health condition is co-morbid with psychological distress: findings from a large cross-sectional sample of working Australians. BMC Public Health. 2011;11:1-9.

56. Millear P, Liossis P, Shochet I, Biggs H, Donald M. Being on PAR: outcomes of a pilot trial to improve mental health and wellbeing in the workplace with the Promoting Adult Resilience (PAR) program. Behav Change. 2008;25: 215-228.

57. Cleary C, Hilton M, Sheridan J, Whiteford H. Organisational barriers preventing the initiation of mental health programs. J Occup Health Saf Aust NZ (CCH Aust). 2008;24:507-517.

58. Hilton MF, Scuffham PA, Sheridan J, et al. The association between mental disorders and productivity in treated and untreated employees. $J$ Occup Environ Med. 2009;51:996-1003

59. Kessler R, Akiskal H, Ames M, Birnbaum H. Prevalence and effects of mood disorders on work performance in a nationally representative sample of U.S. workers. Am J Psychiatry. 2006;163:1561-1568.

60. Goetzel RZ, Long SR, Ozminkowski RJ, et al. Health, absence, disability, and presenteeism cost estimates of certain physical and mental health conditions affecting U.S Employers. J Occup Environ Med. 2004;46: $398-412$

61. Neupane S, Miranda H, Virtanen P, Siukola A, Nygard CH. Multi-site pain and work ability among an industrial population. Occup Med (Oxford England). 2011;61:563-569.

62. Kessler RC, Berglund PA, Coulouvrat C, et al. Insomnia and the performance of US workers: results from the America insomnia survey. Sleep. 2011;34:1161

63. Kessler RC, Maclean JR, Petukhova M, et al. The effects of rheumatoid arthritis on labor force participation, work performance, and healthcare costs in two workplace samples. J Occup Environ Med. 2008;50:88-98.

64. Beales D, Kyaw-Myint S, Smith A, et al. Work productivity loss in young workers is substantial and is associated with spinal pain and mental ill-health conditions. J Occup Environ Med. 2017;59:237-245. 